\title{
The effects of US priming on CR performance and acquisition
}

\author{
WILLIAM S. TERRY and ALLAN R. WAGNER \\ Yale University, New Haven, Connecticut
}

\begin{abstract}
The effects of a pretrial, priming US were investigated in the context of eyeblink conditioning in the rabbit. The administration of a priming US, 4 or $9 \mathrm{sec}$ prior to a CS-US pairing, facilitated the performance of conditioned responding to the CS but decreased the subsequent evidence of conditioning resulting from the pairing. The results are congruent with those from prior studies of CS and US priming in eyeblink conditioning and are consistent with the expectations from a processing model of Pavlovian conditioning (Wagner, 1981) that has been based largely on studies of priming.
\end{abstract}

"Priming" has become a common research tool for investigating stimulus processing and learning, having been employed in a wide range of experimental circumstances involving both human and infrahuman subjects (e.g., Neely, 1977; Pfautz \& Wagner, 1976; Posner \& Synder, 1975; Wagner, 1976). In the general case, assessment is made of how the subject's immediate response to, or learning about, a target stimulus is altered as a function of a shortly preceding exposure to a priming stimulus that has some specifiable associative or identity relationship to the target. The label suggests that a "priming" stimulus may facilitate subsequent processing of the target, as often has been found (e.g., Donegan, 1981; Meyer, Schvaneveldt, \& Ruddy, 1975). However, a substantial literature presents a different picture, indicating that a priming stimulus can decrease the subsequent effectiveness of a similar or associatively related target (e.g., Pfautz \& Wagner, 1976; Terry, 1976).

Studies in our laboratory have used priming to comment upon the mechanism of associative learning and response generation in Pavlovian conditioning, with special concentration upon eyeblink conditioning in the rabbit. Although the priming effects observed within this preparation offer some rich complexities, the major regularities can be summarized easily. When a welltrained conditioned stimulus (CS) is employed as the priming stimulus, preceding the target stimulus by a matter of seconds, it will prominently decrease the effectiveness of the unconditioned stimulus (US) with which it has been trained, either for eliciting an unconditioned response (UR) (Donegan, 1981) or for producing associative learning with another CS (Wagner, 1976). In contrast, the same CS application will prominently increase the conditioned

The research reported was supported in part by National Science Foundation Grant BNS 80-23399 to Allan R. Wagner. W. S. Terry is at the University of North Carolina at Charlotte. Requests for reprints should be addressed to Allan R. Wagner, Department of Psychology, Box 11A Yale Station, Yale University, New Haven, CT 06520. responding observed to another CS that had previously been paired with the same US (Pfautz \& Wagner, 1976). When a US is similarly employed as a priming stimulus, it will produce certain corresponding effects. That is, it will decrease the effectiveness of a repetition of the same US, either for eliciting an UR (Pfautz, 1980) or for producing associative learning with a CS (Terry, 1976). However, whether a priming US will increase conditioned responding to a CS previously paired with that US has not been explicitly evaluated in the eyeblink conditioning situation of particular interest, or in other Pavlovian circumstances.

The present experiment was designed to evaluate the possibility that a priming US would have effects similar to those of a primary CS in producing facilitation of conditioned responding to a CS occurring in a subsequent CSUS episode as well as a decrement in associative learning. According to procedures patterned after those of Terry (1976), two groups of rabbits were trained under the Pavlovian eyeblink paradigm. During the first phase of training, one group received a priming US prior to twothirds of the CS-US pairing episodes, whereas the other group received no priming USs. During the second phase, both groups received a priming US prior to the same twothirds of the CS-US pairs. The between-groups comparison of conditioned responding on equivalent trial types in Phase 2 could be expected to show a relative decrement in conditioning in the initially primed group, as previously demonstrated by Terry (1976). The major question was whether the within-groups comparisons of responding to the CS on primed versus nonprimed trials would also show a contrasting performance-facilitating effect of the priming US.

\section{METHOD}

\section{Subjects}

The subjects were 16 male New Zealand White rabbits, weighing between 1.8 and $2.6 \mathrm{~kg}$ at the start of training. Each was individually housed and maintained with ad-lib food and water. 


\begin{abstract}
Apparatus
Each subject was trained in one of eight identical $66 \times 48 \times 48 \mathrm{~cm}$ isolation chambers. Each chamber was completely lined with aluminum foil to provide a homogeneous visual surround and was illuminated dimly by a $15-\mathrm{W}$ neon light. A background sound-pressure level of $67 \mathrm{~dB}$ (re $20 \mu \mathrm{N} / \mathrm{m}^{2}$ ) was maintained by the presentation of broad-spectrum noise through a $12.7-\mathrm{cm}$ loudspeaker mounted on the rear wall of the chamber. The rabbit was further confined within the chamber by a $51 \times 18$ $\times 14 \mathrm{~cm}$ Plexiglas restraining box through which only its head protruded.

The conditioned stimulus was a $1,100-\mathrm{msec}$ flashing $(15 / \mathrm{sec})$ light, generated by a Knight KG-33 strobe lamp, located behind the subject so as to diffusely reflect from the walls of the chamber. The US was a 100-msec train of $100 / \mathrm{sec} 5-\mathrm{mA}$ square-wave shock pulses produced by an Argonaut LRA-046 constant-current generator and delivered through stainless-steel electrodes sutured about the orbit of the rabbit's right eye. One electrode was implanted approximately $5 \mathrm{~mm}$ below the extreme nasal extent of the eye, and the other approximately $5 \mathrm{~mm}$ above the extreme lateral extent.

Closures of the subject's right eyelid were monitored by a microtorque potentiometer taped to the rabbit's head and communicating with the lid by a length of thread hooked to a small, permanent, gut suture loop. Movements of the eyelid turned a counterweighted wheel affixed to the axle of the potentiometer and were recorded graphically on a Beckman dynograph with an effective gain of four.
\end{abstract}

\section{Procedure}

On the day prior to the start of training, each subject was habituated to confinement in the restraining box outside the conditioning chamber for $2 \mathrm{~h}$. During this time, the rabbit's head was shaved and the two electrodes and suture loop were implanted.

Subsequently, all subjects received six 1-h daily training sessions, each consisting of 12 conditioning trials, with the CS overlapping and terminating with the US, at a mean intertrial interval of $5 \mathrm{~min}$. The differential treatments involved occasions in which scheduled conditioning trials were or were not shortly preceded by a priming presentation of the US (of the same intensity and duration as that which occurred in the trial proper).

For half of the subjects (Group US), the priming manipulation was in force from the beginning of training: One-third of the trials in each session were designated as nonprimed trials, that is, trials involving simple CS-US pairings; the remaining two-thirds of the trials in each session included a pretrial US, either 4 or $9 \mathrm{sec}$ prior to the CS-US pairing. Within a session, the three types of episodes (nonprimed, and 4and 9-sec primed) occurred in each successive 3-trial block via sequences that approximately equated the first-order transitional probabilities among the trial types.

The other half of the subjects (Group N/US) received no priming US prior to any of the CS-US trials during the first three sessions of training. They simply received 12 daily CS-US pairings during this initial phase. In each of the final three sessions, Group N/US then received the same sequence of events that Group US did, so that a priming US was delivered 4 or $9 \mathrm{sec}$ prior to eight of the CS-US trials and the remaining four trials were not primed.

\section{Scoring}

A conditioned response (CR) was scored when the graphic record indicated an eyelid closure of $.5 \mathrm{~mm}$ or more, relative to the pre-CS baseline, during the interval from 140 to $1,000 \mathrm{msec}$ following CS onset. Inspection of the records on US-primed trials showed that the observable eyelid response engendered by the priming US was completed within 1 to $2 \mathrm{sec}$, with the eyelid returning to the resting level well before the following trial. CRs to the CS on both primed and nonprimed occasions were therefore measured with respect to the same baseline.

\section{RESULTS}

Figure 1 presents, for Groups US and N/US, the mean percentages of trials in which a CR was observed, separately for those trials involving a priming US and for

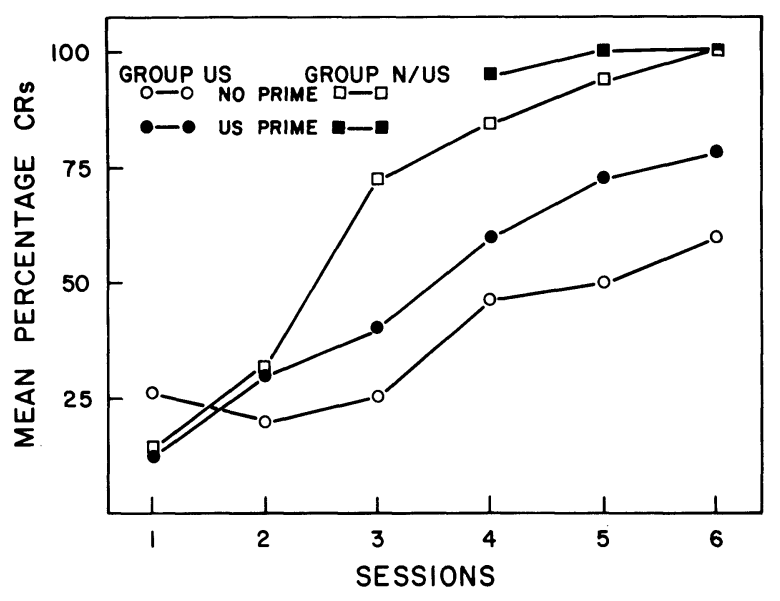

Figure 1. Mean percentages of conditioned eyeblink responses plotted separately for CS-US trials preceded by a priming US and for equivalent trials not preceded by a priming stimulus, in each of two groups. Group US received priming trials in all six sessions, whereas Group N/US received no priming trials until Sessions 4-6.

those with no prime. Since only slight differences in responding were observed between trials in which the priming US occurred 4 versus $9 \mathrm{sec}$ prior, the data are averaged in Figure 1 across these two interval conditions.

There are two sets of comparisons to be made with the present data: Between-groups comparisons to assess the potential decremental effects on acquisition of the priming manipulation used in the initial phase of training, and within-groups comparisons to assess any facilitating effects on CR performance on trials following a priming US. It should be apparent from Figure 1 that both such effects were in evidence.

Looking first at the nonprimed trials of Sessions 1-3, it may be seen that, whereas the two groups did not differ notably at the start of training, by Session 3 Group US was retarded in the development of conditioned responding in comparison with Group N/US. Analysis of variance of these data revealed a reliable groups $\times$ sessions interaction $[F(2,28)=6.73, p<.01]$ and a significant difference between Groups US and N/US on Session 3 $[t(14)=4.43, p<.01]$. Looking further, to Sessions 46 , it is clear that Group US continued to show less evidence of conditioning on nonprimed trials than did Group N/US, and in this phase the same conclusion would be drawn from comparison of primed trials as well. Analysis of variance on the overall difference in conditioned responding across both trial types revealed the significant decrement in Group US as compared with Group N/US on Session $4[F(1,14)=6.16, p<.01]$ and over Sessions 5 and $6[\mathrm{~F}(1,14)=6.96, \mathrm{p}<.01]$ (see related analyses below).

The comparison of responding on US-primed versus nonprimed trials can be made throughout training in Group US, and during Sessions 4-6 in both groups. In Group US, the facilitation of CRs on US-primed trials was first apparent in Session 2 and occurred consistently there- 
after. Analysis revealed a significant overall difference between primed and nonprimed trials $[\mathrm{F}(1,7)=19.08$, $\mathrm{p}<.01]$, a reliable effect of sessions $[\mathrm{F}(5,35)=6.48$, $\mathrm{p}<.01]$, and a reliable interaction $[\mathrm{F}(5,35)=2.55$, $\mathrm{p}$ $<.05]$.

When US-primed trials were first introduced to Group N/US in Session 4, there was a potentiation in CRs on such trials as compared with the nonprimed trials with which the subject had exclusively been trained. The immediacy of this facilitating effect, and the comparability of its magnitude to that in Group US in the same session, is of importance. It could otherwise be supposed that the difference in responding on primed and nonprimed trials in Group US might have developed with some acquired signaling characteristics of the priming stimulus that occurred on the majority of the trials and that, when omitted on nonprimed trials, might have led to a generalization decrement. But such reasoning would not have anticipated a comparable difference in Group N/US on the first occasion of priming. Analysis of variance of the Session 4 data revealed the aforementioned significant overall inferiority of Group US as compared with Group N/US and a reliable facilitation of responding on primed as compared with nonprimed trials $[\mathrm{F}(1,14)=$ $5.65, \mathrm{p}<.05$ ], with no reliable interaction of the two factors $(F<1)$. Separate $t$ tests confirmed that the facilitation on primed versus nonprimed trials was highly reliable both in Group N/US [t(14) $=3.58, \mathrm{p}<.01]$ and in Group US [t $(14)=3.13, \mathrm{p}<.01]$.

Comparable analysis of the performance over Sessions 5 and 6 was rendered relatively mute by the fact that Group N/US was at, or near, $100 \%$ conditioned responding on nonprimed trials and thus could not show additional facilitation of response on primed trials. Analysis of these data showed the above-mentioned overall deficit in responding in Group US as compared with Group N/US, a reliable overall superiority of responding on primed trials versus nonprimed trials $[\mathrm{F}(1,14)=$ $17.37, \mathrm{p}<.01]$, and a groups $\times$ trial type interaction $[\mathrm{F}(1,14)=9.50, \mathrm{p}<.01]$.

It had been anticipated in the design of this experiment that any facilitation of conditioned responding would be more robust when the priming US was administered more proximally, that is, $4 \mathrm{sec}$ rather than $9 \mathrm{sec}$, to the target CS. However, this did not prove to be the case. The overall response rate on primed trials in Group N/US was so consistently high (overall mean $=98.4 \%$ ) that it obscured any potential differences. The conditioned responding on primed trials in Group US was greater on occasions involving a 4 -sec interval (mean $=65.9 \%)$ than on occasions involving a 9-sec interval (mean $=59.6 \%$ ), and consistently so across individual Sessions 3-6. However, the difference was not statistically reliable.

\section{DISCUSSION}

Different Pavlovian conditioning preparations may, by custom or necessity, involve very different parameters of stimulation that could conceivably influence the outcome of a priming analysis. Thus, it has been deemed important to compare various priming effects of interest within the same situation and with comparable stimuli. The results of the present study add to those of Donegan (1981), Pfautz (1980), Pfautz and Wagner (1976), Terry (1976), and Wagner (1976) in the context of eyeblink conditioning in the rabbit and appear to fit into a consistent picture of the effects of CS and US priming. The major question was whether or not US priming could potentiate the conditioned responding to a following CS, analogous to the CS priming effects observed by Pfautz and Wagner. The results were clearly in the affirmative. And the question was experimentally posed so as to allow a determination of whether or not such a performance-facilitating effect could be observed concomitantly with the decremental effect of US priming on CR acquisition as demonstrated by Terry (1976). Again, the results were clearly in the affirmative.

The phenomena demonstrated here are not, however, peculiar to the eyeblink conditioning situation. A substantial literature on instrumental responding had encouraged the expectation that US priming would have the performance-facilitating effect observed here (for reviews, see, e.g., Gallistel, 1973, and Hogan \& Roper, 1978). And in an instrumental runway study similar in conception to the present investigation, Terry (1983) observed the response-facilitating effects of an appetitive reinforcer while also demonstrating a concurrent decremental effect on acquisition.

The model of Pavlovian conditioning that we have developed (e.g., Wagner, 1981) has been influenced importantly by the pattern of results from the available priming studies. Although space does not permit full exposition of the model, we can indicate the general assumptions involved as they bear upon the several priming phenomena that have been mentioned. The model attempts to account for performance and learning in terms of the "activity" that stimulation is assumed to produce in the representative "nodes" (each conceived as a set of informational elements) of a processing system. A key feature of the model is the supposition that there are two distinguishable forms of nodal activity, a primary activity, A1, and a secondary activity, A2. The distinction is made in considering the temporal course of processing following an adequate stimulus: It is assumed that stimulus presentation causes some proportion of the nodal elements that represent a stimulus and are then inactive (I) to be activated to the A1 state, from which they will probabilistically "decay" to the A2 state, before decaying back to I. And the distinction is made in considering the processing consequences of an effective CS and a US: It is assumed that, whereas a US will produce the full, above-mentioned sequence of $\mathrm{A} 1$ and then $\mathrm{A} 2$ activity in the nodal elements that represent the stimulus, the CS, having acquired the capacity to activate the same US node, does not activate the US elements to the A1 state but only to the A2 state. One could say that the A1 process is a relatively immediate perceptual consequence of a stimulus, whereas the $\mathrm{A} 2$ process is a memorial consequence, persisting longer after the stimulus or being engendered by an associated retrieval cue.

On this reasoning, similar effects should be expected when either a US or a CS associated with that US is employed as a priming stimulus, to the degree that either stimulus can cause elements of the US node to be in the A2 state at the time of the subsequent target stimulation. And the nature of the effects should predictably depend upon how the effective processes in the target episode would be modified by the priming-produced A2 state of the US node. Assuming that conditioned responding to a CS reflects the A2 activity of the US node that is engendered (Wagner, 1981), such responding should be facilitated by a priming US as reported here, or by a different priming CS, as reported by Pfautz and Wagner (1976). Assuming that the associative learning (as well as the measured unconditioned responding) produced by a US reflects the Al activity of the US node that is elicited, and assuming that this activity is denied nodal elements that are in the A2 state at the time of US application (Wagner, 1981), such effects of the US should be decreased by a priming US, as reported here and by Pfautz (1980) and Terry (1976), or by a priming CS, as reported by Wagner (1976).

It should be acknowledged that the present data do not, in isolation, demand such an interpretation. For example, the acquisition decrement in Group US as compared with Group N/US could have resulted from alternative mechanisms not experimentally addressed here. However, Terry (1976) could eliminate the possibilities that a similar decrement 
observed in the same preparation was attributable to masking or overshadowing of the target CS, to a reduction in the CS-US contingency, or to backward inhibitory conditioning. Similarly, the CR facilitation produced by US priming could be due to any of several other factors. For example, it could have resulted from a transient increase in the level of general arousal following the priming US (e.g., Killeen, 1975) or to a motivational aftereffect of the prime (e.g., Gallistel, 1973). The present data are of more pointed theoretical significance only when taken in conjunction with the related studies of Donegan (1981), Pfautz (1980), Pfautz and Wagner (1976), Terry, (1976), and Wagner (1976), and thus contribute to an interlocking pattern of priming effects.

There is a final point to be made from the present study that is independent of the particulars of theoretical interpretation. Two effects of US priming were isolated via the experimental comparisons, a decremental effect on CR acquisition and a facilitating effect on CR performance. These two effects could variably work against each other in undifferentiated measures of learned performance under conditions of repeated priming. This may explain why Jenkins, Barnes, and Barrera (1981) observed no overall effects of US priming in an autoshaping situation. And it may help in understanding why massed as compared with spaced trials can variably depress (e.g., Gormezano \& Moore, 1969; Terrace, Gibbon, Farrell, \& Baldock, 1975) or facilitate (e.g., Anderson \& Nakamura, 1964; Cole \& Fantino, 1966) responding. The reconciling observations come from studies, analogous to the present one, that have allowed separate assessments of the consequences of different preceding intertrial intervals upon the learning or performance occasioned by the following trial: Shorter intertrial intervals may produce less CR acquisition (Ewing, Larew, \& Wagner, in press), but may also independently facilitate CR performance (Morris, 1974).

\section{REFERENCES}

ANDerson, N. H., \& NaKamura, C. Y. (1964). Avoidance decrement in avoidance conditioning. Journal of Comparative and Physiological Psychology, 57, 196-204.

Cole, M., \& Fantino, E. (1966). Temporal variables and trial discreteness. Psychonomic Science, 6, 217-218.

DonegaN, N. H. (1981). Priming-produced facilitation or diminution of responding to a Pavlovian unconditioned stimulus. Journal of Experimental Psychology: Animal Behavior Processes, 7, 295-312.

EWING, M. F., LAREW, M. B., \& Wagner, A. R. (in press). Distribution-of-trials-effects in Pavlovian conditioning: An apparent involvement of inhibitory backward conditioning. Journal of Experimental Psychology: Animal Behavior Processes.

GALlistel, C. R. (1973). Self-stimulation: The neurophysiology of reward and motivation. In J. A. Deutsch (Ed.), The physiological basis of memory. New York: Academic Press.

Gormezano, I., \& Moore, J. W. (1969). Classical conditioning. In M. H. Marx (Ed.), Learning: Processes. London: Macmillan.
Hogan, J. A., \& Roper, T. J. (1978). A comparison of the properties of different reinforcers. In J. S. Rosenblatt, R. A. Hinde, C. Beer, \& M. C. Busnel (Eds.), Advances in the study of behavior (Vol. 8). New York: Academic Press.

Jenkins, H. M., BARnes, R. A., \& Barrera, F. J. (1981). Why autoshaping depends on trial spacing. In C. M. Locurto, H. S. Terrace, \& J. Gibbon (Eds.), Autoshaping and conditioning theory. New York: Academic Press.

Killeen, P. (1975). On the temporal control of behavior. Psychological Review, 82, 89-115.

Meyer, D. E., SchVAneveldt, R. W., \& Ruddy, M. G. (1975). Loci of contextual effects in visual word recognition. In P. M. A. Rabbit \& S. Dornic (Eds.), Attention and performance (Vol. 5). London: Academic Press.

MorRIs, R. G. M. (1974). Two independent effects of variation in intertrial interval upon leverpress avoidance learning by rats. Animal Learning \& Behavior, 2, 189-192.

NeELY, J. H. (1977). Semantic priming and retrieval from lexical memory: The roles of inhibitionless spreading activation and limitedcapacity attention. Journal of Experimental Psychology: General, 3, 226-254.

PfaUtz, P. L. (1980). Unconditioned facilitation and diminution of the unconditioned response. Unpublished doctoral dissertation, Yale University.

Pfautz, P. L., \& Wagner, A. R. (1976). Transient variations in responding to Pavlovian conditioned stimuli have implications for mechanisms of "priming." Animal Learning \& Behavior, 4, 107-112.

PoSNER, M. I., \& SNYDER, C. R. R. (1975). Facilitation and inhibition in the processing of signals. In P. M. A. Rabbit \& S. Dornic (Eds.), Attention and performance (Vol. 5). New York: Academic Press.

Terrace, H. S., Gibbon, J., Farrell, L., \& Baldock, M. D. (1975). Temporal factors influencing the acquisition and maintenance of an autoshaped keypeck. Animal Learning \& Behavior, 3, 53-62.

TERRY, W. S. (1976). Effects of priming unconditioned stimulus representation in short-term memory on Pavlovian conditioning. Journal of Experimental Psychology: Animal Behavior Processes, 2, 354-369.

TERRY, W. S. (1983). Effects of food priming on instrumental acquisition and performance. Learning and Motivation, 14, 107-122.

WAGNER, A. R. (1976). Priming in STM: An information processing mechanism for self-generated or retrieval-generated depression in performance. In T. J. Tighe \& R. N. Leaton (Eds.), Habituation: Perspectives from child development, animal behavior, and neurophysiology. Hillsdale, NJ: Erlbaum.

WAGNER, A. R. (1981). SOP: A model of automatic memory processing in animal behavior. In N. E. Spear \& R. R. Miller (Eds.), Information processing in animals: Memory mechanisms. Hillsdale, NJ: Erlbaum.

(Manuscript received for publication August 15, 1984; revision received June 10,1985 .) 